\title{
openheart Impact of preinterventional tricuspid regurgitation on outcome of MitraClip therapy in patients with severely reduced ejection fraction
}

\author{
Takayuki Gyoten (i) , ${ }^{1}$ Daniel Messroghli, ${ }^{2,3}$ Soeren Schenk, ${ }^{1}$ Kristin Rochor, ${ }^{1}$ \\ Oliver Grimmig, ${ }^{1}$ Soeren Just, ${ }^{1}$ Dirk Fritzsche ${ }^{1}$
}

\begin{abstract}
- Additional material is published online only. To view please visit the journal online (http://dx.doi.org/10.1136/ openhrt-2019-001203).
\end{abstract}

To cite: Gyoten T, Messroghli D, Schenk S, et al. Impact of preinterventional tricuspid regurgitation on outcome of MitraClip therapy in patients with severely reduced ejection fraction. Open Heart 2020;7:e001203. doi:10.1136/ openhrt-2019-001203

Received 31 October 2019 Revised 23 January 2020 Accepted 17 February 2020

Check for updates

C) Author(s) (or their employer(s)) 2020. Re-use permitted under CC BY-NC. No commercial re-use. See rights and permissions. Published by BMJ.

${ }^{1}$ Cardiac Surgery, SanaHerzzentrum Cottbus, Cottbus, Brandenburg, Germany ${ }^{2}$ Cardiology, Deutsches Herzzentrum Berlin, Berlin, Germany

${ }^{3}$ Internal Medicine and Cardiology, Charité Universitätsmedizin Berlin, Berlin, Germany

Correspondence to Dr Takayuki Gyoten; t. gyoten29@gmail.com

\section{ABSTRACT}

Aim To evaluate the impact of preinterventional moderate-to-severe functional tricuspid regurgitation (FTR) on early outcome after percutaneous edge-to-edge mitral valve repair (pMVR) with MitraClip procedures for functional mitral regurgitation (FMR) in patients with heart failure with reduced ejection fraction (HFrEF).

Methods and results From January 2013 to December 2017, 80 patients with HFrEF (ejection fraction $22 \% \pm 5.3 \%$ ) and FMR (grade $3.0 \pm 0.36$ ) underwent successful pMVR. The 3-year actuarial survival was $58 \%$. However, $73 \%(n=22)$ of non-survivors died of cardiac failure within 1 year. Patients were categorised into none-to-mild ( $n=36)$ and moderate-to-severe $(n=44)$ postinterventional FTR groups according to pre-MitraClip tricuspid regurgitation grade. Cox regression analysis on 1-year survival demonstrated an impact of FTR severity ( $\mathrm{HR}=1.8,95 \% \mathrm{Cl} 1.01 \%$ to $3.09 \%, \mathrm{p}=0.047$ ), preoperative New York Heart Association class (HR=2.8, 95\% Cl 1.2\% to $6.5 \%, p=0.015)$ and peripheral artery disease $(\mathrm{HR}=5.4$, $95 \% \mathrm{Cl} 1.6$ to $18, \mathrm{p}=0.0054)$. Kaplan-Meier analysis showed that 1-year cardiac death was higher in the moderate-to-severe FTR group ( $p=0.048$ ). In our study, $77 \%$ of pre-MitraClip moderate-to-severe FTR cannot be significantly reduced. Post-MitraClip moderate-to-severe FTR grade was related to lower survival $(p<0.001)$. Conclusion In patients with HFrEF treated with MitraClip for FMR, moderate-to-severe FTR was an independent predictor of cardiac death within 1 year. To improve survival, additional therapy to residual FTR should be considered in early phase after MitraClip therapy.

\section{INTRODUCTION}

Functional tricuspid regurgitation (FTR) is a common finding in the presence of functional mitral valve regurgitation (FMR) ${ }^{1-3}$ In case of moderate-to-severe FTR, tricuspid valve (TV) repair is usually performed simultaneously when patients undergo mitral valve surgery. In the modern era, isolated percutaneous edge-to-edge transcatheter mitral valve repair (pMVR) with the MitraClip system (Abbott Vascular, Menlo Park, California) for FMR in patients with a high

\section{Key questions}

What is already known about this subject?

- Functional tricuspid regurgitation (FTR) is a common finding in the presence of functional mitral valve regurgitation, and untreated moderate-to-severe FTR is known as a predictor of poor survival.

What does this study add?

- In patients with heart failure with reduced ejection fraction undergoing percutaneous edge-to-edge mitral valve repair (pMVR), postinterventional moderateto-severe tricuspid regurgitation (TR) grade was an independent predictor of cardiac death within 1 year.

- $77 \%$ of pre-MitraClip moderate-to-severe FTR cannot be significantly reduced.

How might this impact on clinical practice?

- Residual moderate-to-severe TR might require dedicated additional procedures (an additional TR intervention) even if pMVR was successful.

risk of perioperative mortality and comorbidities is available and has become increasingly favoured over sMVR (surgical mitral valve repair), representing a less invasive beatingheart interventional technique. ${ }^{4-7}$ According to a recent randomised study, early clinical results of pMVR were acceptable in patients with heart failure with reduced ejection fraction (HFrEF).$^{8}$ Concomitant FTR ameliorates by itself in some patients treated for FMR, but remains significant in others. Simultaneous TV edge-to-edge repair (transcatheter mitral plus tricuspid valve edge-to-edge repair) in addition to pMVR has been described but is not routinely performed in clinical practice. In general, untreated moderate-to-severe FTR is known as a predictor of poor survival, yet the prognostic role of FTR severity after pMVR has not yet been investigated. Therefore, the present retrospective study aimed to evaluate the impact of FTR severity in the 
early phase after pMVR in patients with HFrEF and symptomatic FMR.

\section{METHODS}

\section{Patient selection}

Since the start of our MitraClip programme in 2013, individual treatment selection has been based on a multimodal decision-making process based on age, evaluation of surgical risk by logistic EuroSCORE, as well as adjunctive risk evaluation (liver dysfunction, during chemotherapy for malignancy and frailty). In addition, preoperative echocardiography played a critical role in patient selection for MitraClip implantation according to the German Cardiac Society (DGK) criteria. ${ }^{10}$ In selected cases, patients were enrolled in the programme despite extremely poor left ventricular (LV) function (ejection fraction $<15 \%$ ).

\section{Echocardiography}

Transthoracic echocardiography (TTE) data were available for all patients preoperatively. All patients had TEE (Transesophageal echocariography) during MitraClip implantation and at discharge. The TTE examinations were performed by two experienced cardiologists, and all evaluations were carried out according to standard techniques recommended by the American Society of Echocardiography. ${ }^{11}$ Assessment of right ventricular (RV) function was performed from the apical four-chamber view. The severity of tricuspid regurgitation (TR) assessed by Doppler echocardiography was classified as none/ trivial (0), mild (1), moderate (2), moderate-severe (3) or severe (4). Pulmonary artery pressure was also measured by TTE.

\section{pMVR with MitraClip procedure}

Prior to MitraClip implantation, all patients underwent coronary angiography to exclude relevant coronary artery disease necessitating revascularisation. All MitraClip procedures were performed by one experienced interventional cardiologist. All clips (arm length of $9 \mathrm{~mm}$ ) were implanted according to standard practices under general anaesthesia with TEE and fluoroscopic guidance. Additional clips were placed until the residual mitral valve regurgitation (MR) corresponded to a maximum grade of 2 at a mean blood pressure of $60 \mathrm{~mm} \mathrm{Hg}$.

\section{Postoperative course, endpoint and follow-up}

All patients who were treated in our hospital between January 2013 and December 2017 were enrolled. After pMVR, all patients were admitted to the intensive care unit (ICU), before they were further moved to the cardiology ward. The clinical follow-up was closed on 31 December 2018, when the last enrolled patient had completed 1 year of follow-up. The median follow-up was 24 months (IQR: $11-34$ months; range: $0.17-70$ months). Follow-up data of clinical status were obtained from patients' general practitioners or private cardiologists by phone calls and facsimile, and were completed in $98 \%$ of patients. The primary endpoints of the study were 1-year and 3-year survival.

\section{Statistical analysis}

Results are expressed as mean $\pm \mathrm{SD}$ or as median +25 th75th percentile IQR for continuous variables, and frequency and percentage for categorical variables. Univariable comparisons were performed with Student's unpaired t-test for continuous normally distributed data. The Mann-Whitney U test was used for comparisons of non-parametric continuous data and Fisher's exact test for categorical data. Data for survival and freedom from cardiac events and all-cause death were derived using the Kaplan-Meier method; comparisons were made using the log-rank test. The association between postinterventional TR severity and occurrence rate of 1-year cardiovascular event (cardiac death) was evaluated with Cox regression analysis, and the results were expressed as HR with 95\% CI. Candidate covariates were chosen based on previous medical knowledge; then, a backward stepwise selection was performed. Differences were considered statistically significant at $\mathrm{p}<0.05$. Statistical analysis was performed using SPSS for Windows V.22.0.

\section{RESULTS}

\section{Study cohort and characteristics}

Eighty-five patients with moderate-to-severe FMR and HFrEF $(\leq 30 \%)$ were treated with pMVR in our hospital between January 2013 and December 2017. Patients with acute emergency treatment, redo-pMVR, organic mitral or TV disease and those who were lost to follow-up $(n=2)$ were excluded. Moreover, three $(3.5 \%)$ patients with unsuccessful pMVR (defined as postoperative MR grade of 3 or more) were also excluded for the purpose of surveying the accurate impact of pMVR, resulting in 80 patients (age $72 \pm 8.7$ years, $60 \%$ male) with end-stage cardiomyopathy (non-ischaemic $\mathrm{n}=41$; ischaemic $\mathrm{n}=39$ ) who underwent MitraClip therapy. Left ventricular ejection fraction (LVEF) showed a mean of $22 \% \pm 5.3 \%$. Preoperative echocardiography showed LVEF $\leq 15 \%$ in $13(16 \%)$ patients. Baseline TR had a mean grade of $1.63 \pm 0.75$. The characteristics of baseline and preoperative echocardiography are shown in tables 1 and 2.

\section{Predictors of early cardiac death}

The Kaplan-Meier estimate for overall survival at 3 years was $57.4 \%$. Survival rate at 1-year follow-up was $72.5 \%$. All these 22 patients died of cardiac death within 1 year, although pMVR was successful (figure 1). Multivariate Cox regression analysis for 1-year survival identified preoperative TR grade (HR=1.765, 95\% CI 1.007 to 3.093, $\mathrm{p}=0.047$ ), preoperative New York Heart Association (NYHA) grade (HR=2.811, 95\% CI 1.222 to 6.469 , $\mathrm{p}=0.015)$ and peripheral artery disease $(\mathrm{HR}=5.376$, $95 \%$ CI 1.642 to $17.6, \mathrm{p}=0.0054)$ as independent predictors at 1-year survival (table 3 ). Other variables including ischaemic versus non-ischaemic origin, preoperative 


\begin{tabular}{|c|c|}
\hline Variables & Total $(\mathbf{N}=80)$ \\
\hline Age, mean $\pm S D$ (years) & $72 \pm 8.7$ \\
\hline Male gender & $60(75)$ \\
\hline Body mass index, mean $\pm \mathrm{SD}\left(\mathrm{kg} / \mathrm{m}^{2}\right)$ & $26 \pm 4.7$ \\
\hline Diabetes mellitus & $34(43)$ \\
\hline Arterial hypertension & $72(90)$ \\
\hline COLD & $14(18)$ \\
\hline PAD & $9(11)$ \\
\hline Stroke & $16(20)$ \\
\hline Chronic renal disease & $33(41)$ \\
\hline Ischaemic cardiomyopathy & $39(49)$ \\
\hline Dilated cardiomyopathy & $41(51)$ \\
\hline Previous percutaneous coronary intervention & $34(43)$ \\
\hline Percutaneous coronary intervention within 3 months & $12(15)$ \\
\hline Previous cardiac surgery & $25(31)$ \\
\hline Previous CRT & $33(41)$ \\
\hline Previous ICD & $42(53)$ \\
\hline NYHA functional class, mean \pm SD & $3.3 \pm 0.46$ \\
\hline Atrial fibrillation & $49(61)$ \\
\hline Logistic EuroSCORE, mean \pm SD & $34 \pm 20$ \\
\hline EuroSCORE, mean \pm SD & $16 \pm 13$ \\
\hline \multicolumn{2}{|l|}{ Medication } \\
\hline ACE inhibitor/ARB & $64(80)$ \\
\hline Beta-blocker & $68(85)$ \\
\hline Mineralocorticoid receptor antagonist & $59(74)$ \\
\hline Loop diuretics & $76(95)$ \\
\hline Digitoxin & $21(26)$ \\
\hline
\end{tabular}

$\mathrm{n}(\%)$ if not otherwise specified.

ARB, angiotensin receptor blocker; COLD, chronic obstructive lung disease; CRT, cardiac resynchronisation therapy; ICD, implanted cardioverter defibrillator; NYHA, New York Heart Association; PAD, peripheral artery disease.

LVEF, and other parameters of echocardiography were not found as predictors.

\section{Preprocedural characteristics and periprocedural results according to TR grade}

According to preoperative TR severity, this cohort was divided into none-to-mild FTR group (36 patients, 45\%) and moderate-to-severe FTR group (44 patients, 55\%) (TR grade: $0.92 \pm 0.28$ vs $2.2 \pm 0.42, \mathrm{p}<0.001)$. When comparing these two groups, there were no significant differences in preoperative characteristics and echocardiography, including the parameters of RV dimension, pulmonary artery hypertension and tricuspid annual plane systolic excursion. The details of the baseline characteristics of the two groups are shown in table 4. In-hospital death occurred in two $(2.5 \%)$ patients, regardless of extracorporeal membrane oxygenation and intra-aortic balloon pump, because of postoperative cardiogenic shock state,
Table 2 Baseline results of transthoracic echocardiography in the full cohort

\begin{tabular}{|c|c|}
\hline Variables & Total $(\mathrm{N}=80)$ \\
\hline LVEF (\%) & $22 \pm 5.3$ \\
\hline MR grade & $3.0 \pm 0.36$ \\
\hline LVDd (mm) & $73 \pm 6.4$ \\
\hline LVDs (mm) & $66 \pm 7.1$ \\
\hline LA (mm) & $54 \pm 8.4$ \\
\hline LVEDV (mL) & $242 \pm 69$ \\
\hline LVESV (mL) & $182 \pm 64$ \\
\hline $\operatorname{EDVI}\left(\mathrm{mL} / \mathrm{m}^{2}\right)$ & $129 \pm 39$ \\
\hline ESVI $\left(\mathrm{mL} / \mathrm{m}^{2}\right)$ & $97 \pm 35$ \\
\hline TR grade & $1.63 \pm 0.75$ \\
\hline RVDd (mm) & $39 \pm 6.4$ \\
\hline RVDs (mm) & $34 \pm 6.2$ \\
\hline Systolic pulmonary artery $(\mathrm{mm} \mathrm{Hg})$ & $54 \pm 15$ \\
\hline TAPSE (mm) & $14 \pm 4.65$ \\
\hline $\operatorname{RVESP}(\mathrm{mm} \mathrm{Hg})$ & $44 \pm 15$ \\
\hline
\end{tabular}

Results expressed as mean \pm SD.

EDVI, end-diastolic volume index; ESVI, end-systolic volume index; LA, left atrium; LVDd, left ventricular diastolic diameter; LVDs, left ventricular systolic diameter; LVEDV, left ventricular enddiastolic volume; LVEF, left ventricular ejection fraction; LVESV, left ventricular end-systolic volume; MR, mitral valve regurgitation; RVDd, right ventricular diastolic diameter; RVDs, right ventricular systolic diameter; RVESP, right ventricular end-systolic pressure; TAPSE, tricuspid annular plane systolic excursion; TR, tricuspid valve regurgitation.

although postoperative MR severity was reduced to an MR grade of 1 . Of these, one patient with a TR grade of 1 had a preoperative high value of logistic EuroSCORE of $44 \%$ with LVEF of $10 \%$ and died after 8 days. The other

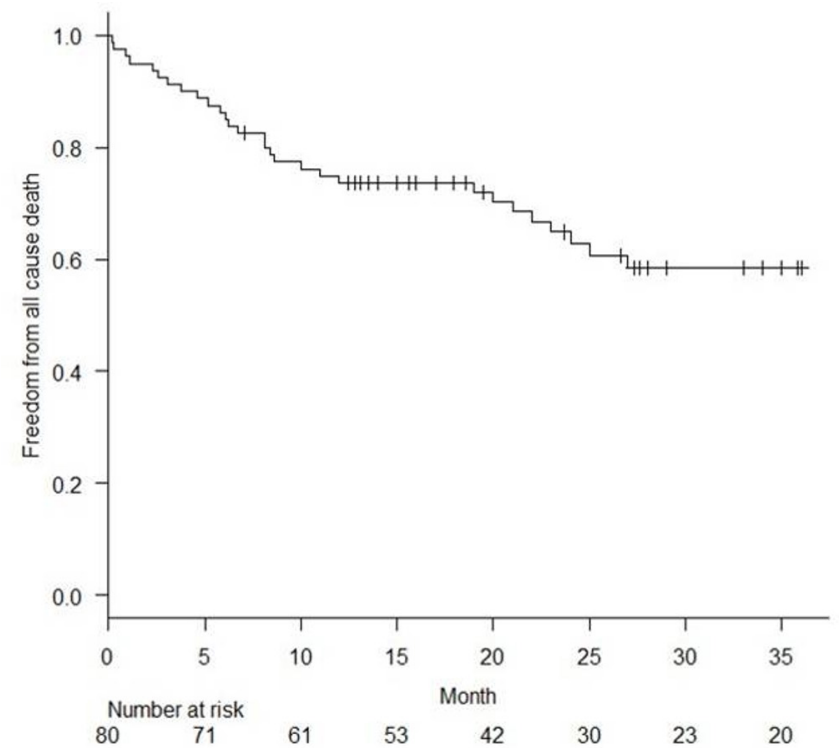

Figure 1 Clinical outcome of the full cohort. Kaplan-Meier curves for freedom from all-cause death estimated at $72.5 \%$ at 1 year and $57.4 \%$ at 3 years. 
Table 3 Cox regression model analysis for cardiac death at 1 -year follow-up

\begin{tabular}{|c|c|c|c|c|}
\hline & \multicolumn{2}{|c|}{ Univariate analysis } & \multicolumn{2}{|c|}{ Multivariate analysis } \\
\hline & $\begin{array}{l}\text { HR } \\
(95 \% \mathrm{Cl})\end{array}$ & $P$ value & $\begin{array}{l}\text { HR } \\
(95 \% \mathrm{Cl})\end{array}$ & $P$ value \\
\hline $\begin{array}{l}\text { Preoperative TR } \\
\text { grade }\end{array}$ & $\begin{array}{l}1.72 \\
(0.98 \text { to } 3.00)\end{array}$ & 0.058 & $\begin{array}{l}1.77 \\
\text { (1.01 to } 3.09)\end{array}$ & 0.047 \\
\hline NYHA grade & $\begin{array}{l}2.54 \\
\text { (1.08 to } 5.94)\end{array}$ & 0.032 & $\begin{array}{l}2.81 \\
\text { (1.22 to } 6.47)\end{array}$ & 0.015 \\
\hline PAD & $\begin{array}{l}3.11 \\
\text { (1.13 to } 8.53)\end{array}$ & 0.028 & $\begin{array}{l}5.376 \\
\text { (1.64 to 17.6) }\end{array}$ & 0.0054 \\
\hline $\begin{array}{l}\text { Preoperative } \\
\text { LVEF }\end{array}$ & $\begin{array}{l}0.94 \\
\text { (0.86 to } 1.02)\end{array}$ & 0.148 & & \\
\hline LogEurOSCORE & $\begin{array}{l}1.01 \\
\text { (0.99 to } 1.04)\end{array}$ & 0.176 & & \\
\hline
\end{tabular}

LVEF, left ventricular ejection fraction; NYHA, New York Heart Association; PAD, peripheral artery disease; TR, tricuspid valve regurgitation.

patient with a TR grade of 2 had high surgical risk of $30 \%$ with LVEF of $17 \%$ and died after 5 days.

There were no cases of postoperative cardiac tamponade or new pacemaker implantation. There was no significant difference in postoperative MR severity $(p=0.37)$ between the two groups. However, there was a trend towards higher number of implanted clips in the moderate-to-severe TR group ( $2.23 \pm 0.71$ vs $1.92 \pm 0.69$, respectively; $\mathrm{p}=0.053)$. In addition, extubation rate in the hybrid room $(\mathrm{p}=0.28)$, duration of ICU stay $(\mathrm{p}=0.39)$ and total hospital stay $(\mathrm{p}=0.24)$ were not significantly different between the two groups. The discharge rate to home was similar at $89 \%$ in both groups. Intraprocedural results and periprocedural outcomes are presented in table 5 .

\section{Clinical impact of preprocedural TR severity}

In the Kaplan-Meier analysis, the rates of freedom from cardiac death were significantly higher for preprocedural none-to-mild TR group at 1-year follow-up $(\mathrm{p}=0.048)$ (online supplementary figure 1). Clinical outcomes at 1-year follow-up are shown in table 6. Between the two groups, there were significant differences in rehospitalisation due to heart failure $(\mathrm{p}=0.021)$ and trend towards higher cardiac death $(\mathrm{p}=0.077)$. A total of five patients required $L V$ assist device implantation $(n=2)$ or mitral valve replacement $(n=3)$ due to clip failure at 1-year follow-up, but this was not significantly different between the two groups. NYHA grade of survivors at 1 year was not statistically different.

\section{Postprocedural TR grade influencing survival}

Postprocedural moderate-to-severe FTR grade was noted in $38(47.5 \%)$ patients. The low TR grade in the noneto-mild pre-MitraClip TR group was preserved postMitraClip $(0.92 \pm 0.28$ vs $1.03 \pm 0.45, \mathrm{p}=0.103)$, whereas the TR grade of the moderate-severe group significantly improved (2.23 \pm 0.42 vs $1.93 \pm 0.62, \mathrm{p}=0.0034)$. Online supplementary figure $2 \mathrm{~A}, \mathrm{~B}$ shows the alteration of TR
Table 4 Preprocedural characteristics and echocardiography between none/mild and moderate/severe TR grade

\begin{tabular}{llll|}
\hline & $\begin{array}{l}\text { None/mild } \\
\text { TR, } \mathbf{n = 3 6}\end{array}$ & $\begin{array}{l}\text { Moderate/severe } \\
\text { TR, } \mathbf{n = 4 4}\end{array}$ & P value \\
\hline Age, mean \pm SD (years) & $70 \pm 8.3$ & $73 \pm 8.8$ & 0.08 \\
\hline Male gender & 25 & 35 & 0.31 \\
\hline PAD & 3 & 6 & 0.50 \\
\hline Chronic renal disease & 15 & 18 & 1 \\
\hline Diabetes mellitus & 16 & 18 & 0.82 \\
\hline Dilated cardiomyopathy & 18 & 23 & 1 \\
\hline $\begin{array}{l}\text { Ischaemic cardiomyopathy } \\
\text { NYHA functional class, }\end{array}$ & 18 & 21 & 1 \\
mean \pm SD & $3.3 \pm 0.45$ & $3.2 \pm 0.48$ & 0.63 \\
\hline $\begin{array}{l}\text { Previous CRT } \\
\text { Previous ICD }\end{array}$ & 16 & 17 & 0.65 \\
\hline $\begin{array}{l}\text { Logistic EuroSCORE, } \\
\text { mean } \pm S D\end{array}$ & $32 \pm 21$ & $36 \pm 19$ & 0.82 \\
\hline
\end{tabular}

Echocardiography

\begin{tabular}{lllc} 
LVEF, mean $\pm S D(\%)$ & $23 \pm 5.1$ & $22 \pm 5.5$ & 0.56 \\
MR grade, mean $\pm S D$ & $2.9 \pm 0.33$ & $3.0 \pm 0.37$ & 0.21 \\
TR grade, mean $\pm S D$ & $0.92 \pm 0.28$ & $2.2 \pm 0.42$ & $<0.001$ \\
LVDd, mean $\pm S D(m m)$ & $73 \pm 7.2$ & $73 \pm 5.7$ & 0.98 \\
LVDs, mean $\pm S D(m m)$ & $65 \pm 8.0$ & $66 \pm 6.3$ & 0.43 \\
LA, mean $\pm S D(m m)$ & $52 \pm 6.9$ & $55 \pm 9.3$ & 0.12 \\
$\begin{array}{l}\text { EDVI, mean } \pm S D(m L / \\
\left.m^{2}\right)\end{array}$ & $131 \pm 41$ & $127 \pm 37$ & 0.60 \\
$\begin{array}{l}\text { ESVI, mean } \pm S D(m L / \\
\left.m^{2}\right)\end{array}$ & $97 \pm 36$ & $96 \pm 35$ & \\
RVDd, mean $\pm S D(m m)$ & $39 \pm 6.4$ & $40 \pm 6.5$ & 0.88 \\
RVDs, mean $\pm S D(m m)$ & $33 \pm 6.2$ & $34 \pm 6.2$ & 0.41 \\
$\begin{array}{l}\text { Systolic pulmonary } \\
\text { artery (mm Hg) }\end{array}$ & $54 \pm 17$ & $55 \pm 14$ & 0.27 \\
TAPSE, mean $\pm S D(m m)$ & $15 \pm 4.8$ & $14 \pm 4.5$ & 0.73 \\
$\begin{array}{l}\text { RVESP, mean } \pm S D(m m \\
\text { Hg) }\end{array}$ & $52 \pm 17$ & $56 \pm 14$ & 0.40 \\
\hline
\end{tabular}

CRT, cardiac resynchronisation therapy; EDVI, end-diastolic volume index; ESVI, end-systolic volume index; ICD, implanted cardioverter defibrillator; LA, left atrium; LEVF, left ventricular ejection fraction; LVDd, left ventricular diastolic diameter; LVDs, left ventricular systolic diameter; MR, mitral valve regurgitation; NYHA, New York Heart Association; PAD, peripheral artery disease; RVDd, right ventricular diastolic diameter; RVDs, right ventricular systolic diameter; RVESP, right ventricular end-systolic pressure; TAPSE, tricuspid annual plane systolic excursion; TR, tricuspid regurgitation.

grade before and after MitraClip therapy. Overall, TR grade was reduced in $16(20 \%)$ patients, preserved in $56(70 \%)$ and increased in $8(10 \%)$. Preprocedural moderate-to-severe TR grade was decreased to mild TR grade in $10(23 \%)$ patients, but no improvement in TR grade in $34(77 \%)$ patients postprocedure. In the KaplanMeier analysis, the rates of freedom from all-cause death were significantly higher for postprocedural none-to-mild FTR group at 1 and 3 years of follow-up ( $p=0.0007$ and $\mathrm{p}=0.0020$, respectively) (online supplementary figure 3 ). 


\begin{tabular}{|c|c|c|c|}
\hline & $\begin{array}{l}\text { None/mild } \\
\text { TR, } n=36\end{array}$ & $\begin{array}{l}\text { Moderate/severe, } \\
\text { TR } n=44\end{array}$ & P value \\
\hline In-hospital death & $1(2.8)$ & $1(2.3)$ & 1 \\
\hline $\begin{array}{l}\text { Postoperative MR } \\
\text { grade, mean } \pm S D\end{array}$ & $1.25 \pm 0.55$ & $1.36 \pm 0.57$ & 0.37 \\
\hline $\begin{array}{l}\text { Postoperative TR } \\
\text { grade, mean } \pm S D\end{array}$ & $1.03 \pm 0.45$ & $1.93 \pm 0.62$ & $<0.0001$ \\
\hline MitraClip, mean \pm SD & $1.92 \pm 0.69$ & $2.23 \pm 0.71$ & 0.053 \\
\hline Hybrid extubation & $34(94)$ & $38(86)$ & 0.28 \\
\hline ECMO & $1(2.8)$ & $0(0)$ & 1 \\
\hline IABP & $1(2.8)$ & $1(2.3)$ & 1 \\
\hline Tamponade & $0(0)$ & $0(0)$ & 1 \\
\hline $\begin{array}{l}\text { ICU stay, mean } \pm \text { SD } \\
\text { (days) }\end{array}$ & $1.22 \pm 1.2$ & $1.55 \pm 2.0$ & 0.39 \\
\hline $\begin{array}{l}\text { Hospital stay, } \\
\text { mean } \pm S D \text { (days) }\end{array}$ & $5.3 \pm 2.2$ & $6.2 \pm 3.8$ & 0.24 \\
\hline \multicolumn{4}{|l|}{ Discharge } \\
\hline To home & $32(89)$ & $39(89)$ & 1 \\
\hline To rehabilitation & $0(0)$ & $4(9.1)$ & 0.12 \\
\hline To stroke unit & $0(0)$ & $0(0)$ & 1 \\
\hline Cardiology & $3(8.3)$ & $0(0)$ & 0.090 \\
\hline
\end{tabular}

$\mathrm{n}(\%)$ if not otherwise specified.

There were no cases of myocardial infarction or AV blockage. $\mathrm{AV}$, atrioventricular; ECMO, extracorporeal membrane oxygenation; IABP, intra-aortic balloon pump; ICU, intensive care unit; MR, mitral valve regurgitation; TR, tricuspid valve regurgitation.

Moreover, in 34 patients with preoperative moderate-tosevere TR grade, all-cause survival rate was significantly higher in the 15 patients with postoperatively improved TR grade than in the 19 patients with non-improved TR grade at 1 and 3 years of follow-up $(\mathrm{p}=0.031$ and $\mathrm{p}=0.012$, respectively). Meanwhile, preprocedural none-to-mild TR grade was increased to moderate-to-severe TR grade in four patients $(11.1 \%$ ) (online supplementary figure $2 \mathrm{~A})$. One of these four patients died of heart failure during follow-up.

\begin{tabular}{|c|c|c|c|}
\hline & $\begin{array}{l}\text { None/mild } \\
\text { TR, } n=36\end{array}$ & $\begin{array}{l}\text { Moderate/severe } \\
\text { TR, } n=44\end{array}$ & $P$ value \\
\hline $\begin{array}{l}\text { In-hospitalisation for } \\
\text { heart failure }\end{array}$ & $8(22)$ & $21(48)$ & 0.021 \\
\hline Cardiac death & $6(17)$ & $16(36)$ & 0.077 \\
\hline Second MitraClip & $1(2.8)$ & $2(4.5)$ & 1 \\
\hline $\begin{array}{l}\text { Surgical mitral valve } \\
\text { revision }\end{array}$ & $1(2.8)$ & $2(4.5)$ & 1 \\
\hline LVAD implantation & $0(0)$ & $2(4.5)$ & 0.50 \\
\hline $\begin{array}{l}\text { NYHA grade of } \\
\text { survivors }\end{array}$ & $\begin{array}{l}2.5 \pm 0.88 \\
(n=28)\end{array}$ & $2.37 \pm 0.69(n=27)$ & 0.55 \\
\hline
\end{tabular}

LVAD, left ventricular assist device; NYHA, New York Heart Association; TR, tricuspid regurgitation.
Table 7 Cox regression model analysis for cardiac death at 1 -year follow-up in ICM and DCM groups

\begin{tabular}{|c|c|c|c|c|}
\hline & \multicolumn{2}{|c|}{ Univariate analysis } & \multicolumn{2}{|c|}{ Multivariate analysis } \\
\hline & $\begin{array}{l}\text { HR } \\
(95 \% \mathrm{Cl})\end{array}$ & $P$ value & $\begin{array}{l}\text { HR } \\
(95 \% \mathrm{Cl})\end{array}$ & $\begin{array}{l}P \\
\text { value }\end{array}$ \\
\hline \multicolumn{5}{|l|}{ ICM } \\
\hline $\begin{array}{l}\text { Postprocedural } \\
\text { TR grade }\end{array}$ & $\begin{array}{l}1.75 \\
\text { (0.6999 to } 4.378)\end{array}$ & 0.2313 & & \\
\hline NYHA grade & $\begin{array}{l}1.56 \\
\text { (0.4277 to } 5.702)\end{array}$ & 0.4999 & & \\
\hline LogEuroSCORE & $\begin{array}{l}1.008 \\
\text { (0.9723 to } 1.046)\end{array}$ & 0.6576 & & \\
\hline \multicolumn{5}{|l|}{ DCM } \\
\hline $\begin{array}{l}\text { Postprocedural } \\
\text { TR grade }\end{array}$ & $\begin{array}{l}2.611 \\
\text { (1.287 to } 5.295)\end{array}$ & 0.0078 & $\begin{array}{l}2.611 \\
\text { (1.287 to } 5.295)\end{array}$ & 0.0078 \\
\hline NYHA grade & $\begin{array}{l}3.579 \\
(1.193 \text { to } 10.74)\end{array}$ & 0.0229 & & \\
\hline LogEuroSCORE & $\begin{array}{l}1.025 \\
\text { (0.9999 to } 1.051)\end{array}$ & 0.0505 & & \\
\hline
\end{tabular}

DCM, dilated cardiomyopathy; ICM, ischaemic cardiomyopathy; NYHA, New York Heart Association; TR, tricuspid regurgitation.

\section{Clinical impact of postoperative moderate-to-severe TR in ischaemic versus non-ischaemic cardiomyopathy}

Survival rate for all-cause death between the ischaemic and non-ischaemic groups, regardless of residual TR severity, was not significantly different (online supplementary figure 4A,B). Multivariate Cox regression analysis identified postprocedural TR grade as an independent predictor of 1-year survival in the non-ischaemic group, but not in the ischaemic group (table 7). In the Kaplan-Meier analysis, survival rate for all-cause death at 1 and 3 years of follow-up was not significantly different between patients with ischaemia with postoperative noneto-mild TR and those with postoperative moderate-tosevere TR ( $p=0.125$ and 0.0748 , respectively), but it was significantly different among the non-ischaemic patients ( $p=0.00426$ and $p=0.00433$, respectively) (online supplementary figure $4 \mathrm{C}, \mathrm{D})$.

\section{DISCUSSION}

We studied the impact of FTR in patients with HFrEF (LVEF $\leq 30 \%$ ) with high surgical risk undergoing pMVR.

The main findings of the current study are as follows. First, the periprocedural mortality $(2.5 \%)$ is acceptable and not affected by FTR severity in patients with HFrEF. Second, preprocedural moderate-to-severe FTR grade is an independent predictor of cardiac death at 1 year in patients with HFrEF, even if the MitraClip therapy is successful with regard to the reduction of FMR. Third, residual moderate-to-severe FTR grade is a predictor of cardiac death at 1 year and all-cause mortality at midterm follow-up in patients with non-ischaemic, but not in ischaemic cardiomyopathy.

Residual moderate-to-severe FTR grade was significantly associated with early mortality. In our cohort, only 
$23 \%$ of cases with preoperative moderate-to-severe FTR grade could be reduced to mild FTR by pMVR, leaving $77 \%$ of patients at high risk of early mortality. As pMVR alone is not able to relieve FTR effectively in these patients, an additional intervention reducing FTR might be necessary in order to address left-sided and right-sided heart disease individually.

FTR is caused by TV annular dilation ${ }^{12}$ and is often related to increased tethering of tricuspid leaflets due to RV enlargement owing to pulmonary hypertension. ${ }^{1314}$ A reported echocardiographic study emphasised that moderate-to-severe TR can increase the mortality rate regardless of pulmonary hypertension or low ejection fraction. ${ }^{15}$ According to the literature, dilation of the right ventricle correlates with poor prognosis in patients with severe LV dysfunction. ${ }^{16}$ In our two groups, none of the echocardiographic variables assessed were significantly different except for TR severity (table 2). Although there is no information about TV annulus diameter, we considered that these two groups might be different in terms of the preoperative TV annulus diameter influencing the FTR severity. However, it should be noted that the function of the right ventricle cannot be easily quantified by echocardiography due to its complex geometry. Recent studies have described that severe FTR or pulmonary hypertension may increase mortality after MitraClip procedure. ${ }^{17} 18$ In our cohort with severely reduced LV systolic function, mild-to-severe preinterventional FTR was a predictor of mortality after MitraClip therapy, but not pulmonary hypertension. Postcapillary pulmonary hypertension as an immediate consequence of MR usually decreases after the procedure, whereas $\mathrm{TR}$, reflecting sustained RV volume and pressure overload, seems to represent a structural defect in itself when present. The relation between efficiency of MitraClip and pulmonary artery pressure over time needs to be further studied.

Although our study was performed at a single centre, our outcomes reflect real-world practice, at least for highvolume centres in Germany. Our patients had severe LV dysfunction (mean LVEF of $22 \% \pm 5.3 \%$ ), as reflected by a high risk for surgical mortality (mean logEuroSCORE $34 \% \pm 20 \%$ ). Our clinical outcomes compared well with a previous large cohort study. ${ }^{8}$

In our cohort, $55 \%$ of patients had preoperative moderate-to-severe TR grade, yet the difference in preoperative TR severity did not have any influence on perioperative mortality (table 5) or duration of ICU stay $(1.22 \pm 1.2$ vs $1.55 \pm 2.0$ days, $\mathrm{p}=0.39)$. The proportions of patients with none-to-mild FTR and those with moderateto-severe FTR who were discharged home were $88.9 \%$ and $88.6 \%$, respectively ( $\mathrm{p}=\mathrm{ns}$ ), showing that $\mathrm{pMVR}$ can be safely performed in patients with HFrEF and high surgical risk.

Some authors have suggested that moderate-to-severe FTR in patients undergoing mitral valve surgery alone is strongly related to lower survival at midterm follow-up. ${ }^{19}$ Generally, the residual MR grade after pMVR is greater than that after mitral valve surgery. Therefore, residual FTR severity is difficult to be reduced and seems to have more significant influence on cardiac death. In patients with HFrEF with postprocedural moderate-to-severe TR, attempts to treat FTR need to be discussed, even if pMVR is successful. Interestingly, $77 \%$ of patients with preprocedural moderate-to-severe FTR showed no improvement in FTR postoperatively and more than $40 \%$ died within 1 year because of heart failure. Echocardiographic variables of our two groups were similar, except for TR severity (table 4). As suggested in our study, preprocedural FTR severity seems to be an important predictor of poor survival.

Interestingly, early survival was not related to residual TR grade in patients with ischaemic cardiomyopathy (ICM), but was in patients with dilated cardiomyopathy (DCM). Most published reports concluded that survival both in patients with DCM and in patients with ICM is similar at midterm follow-up, which is in line with the findings of our study. ${ }^{20}$ However, this was not differentiated by residual TR severity so far. We hypothesise that high-grade residual TR in DCM represents a risk factor in itself and should be considered a therapeutic target in order to improve survival in patients with DCM.

As recent studies have suggested that transcatheter tricuspid edge-to-edge repair (TTVR) can reduce the severity of FTR, ${ }^{21}$ future studies should investigate if TTVR can improve survival in patients with residual moderateto-severe FTR after pMVR in patients with HFrEF. We suggest that patients with moderate-to-severe preprocedural FTR should be observed carefully after MitraClip procedure. If FTR does not improve, additional interventional therapy should be considered early.

\section{Limitations}

This observational study was conducted at a single centre. Although patients were selected from a real-world clinical setting, the patient population was relatively small and the follow-up duration was relatively short. There were no CMR (Cardiovascular magnetic resonance) data available which would have allowed for more advanced analysis of RV function. In our study, preoperative NYHA grade was identified as an independent predictor of 1-year survival. However, preoperative NYHA grade might not entirely represent heart failure because of severe frailty in this cohort.

\section{CONCLUSION}

MitraClip therapy in patients with HFrEF was safe, regardless of preoperative FTR severity. However, preoperative FTR was not significantly improved. In our study, preoperative FTR was a major predictor of cardiac death at 1-year follow-up. Future studies are necessary to determine the value of additional TTVR in patients with residual moderate-to-severe FTR in the early phase after pMVR.

Contributors All persons who meet the authorship criteria are listed as authors, and all authors certify that they have participated sufficiently in the work to take 
public responsibility for the content, including participation in the concept, design, analysis, writing or revision of the manuscript. Furthermore, each author certifies that this material or similar material has not been and will not be submitted to or published in any other publication before its appearance in Open Heart. TG, DM: conception or design of the work, and acquisition, analysis and interpretation of data for the work. SS, KR, OG, SJ: conception or design of the work, and agreement to be accountable for all aspects of the work. DF, DM: final approval of the version to be published and agreement to be accountable for all aspects of the work.

Funding The authors have not declared a specific grant for this research from any funding agency in the public, commercial or not-for-profit sectors.

Competing interests None declared.

Patient consent for publication Not required.

Ethics approval This single-centre study was approved by the Institutional Review Board of Sana Heart Center in Cottbus (Germany). The study complied with the Declaration of Helsinki. The study protocol was discussed with local ethics authorities (Ärztekammer Brandenburg, Germany), and ethical approval was waived due to the retrospective design of the study.

Provenance and peer review Not commissioned; externally peer reviewed.

Data availability statement Data are available in a public, open access repository. Data are available upon reasonable request. All data relevant to the study are included in the article or uploaded as supplementary information. Upon receiving approval from the Institutional Review Board of the Sana Heart Center, we retrospectively reviewed the records of consecutive patients who, between January 2013 and January 2018, had undergone medication therapy alone, repeat MitraClip therapy, or surgical revision for persistent or recurrent MR after percutaneous MitraClip therapy.

Open access This is an open access article distributed in accordance with the Creative Commons Attribution Non Commercial (CC BY-NC 4.0) license, which permits others to distribute, remix, adapt, build upon this work non-commercially, and license their derivative works on different terms, provided the original work is properly cited, appropriate credit is given, any changes made indicated, and the use is non-commercial. See: http://creativecommons.org/licenses/by-nc/4.0/.

ORCID iD

Takayuki Gyoten http://orcid.org/0000-0002-7960-6704

\section{REFERENCES}

1 Mirabel M, lung B, Baron G, et al. What are the characteristics of patients with severe, symptomatic, mitral regurgitation who are denied surgery? Eur Heart J 2007;28:1358-65.

2 Jamieson WR, Edwards FH, Schwartz M, et al. Risk stratification for cardiac valve replacement. National cardiac surgery database. database Committee of the Society of thoracic surgeons. Ann Thorac Surg 1999;67:943-51.

3 Bach DS, Awais M, Gurm HS, et al. Failure of guideline adherence for intervention in patients with severe mitral regurgitation. J Am Coll Cardiol 2009;54:860-5.

4 Sorajja P, Vemulapalli S, Feldman T, et al. Outcomes with transcatheter mitral valve repair in the United States: an STS/ACC TVT Registry report. J Am Coll Cardiol 2017;70:2315-27.
5 Sorajia P, Mack M, Vemulapalli S, et al. Initial experience with commercial transcatheter mitral valve repair in the United States. $J$ Am Coll Cardiol 2016;67:1129-40.

6 Grover FL, Vemulapalli S, Carroll JD, et al. 2016 Annual Report of The Society of Thoracic Surgeons/American College of Cardiology Transcatheter Valve Therapy Registry. J Am Coll Cardiol 2017:69:1215-30.

7 Baldus S, Schillinger W, Franzen O, et al. MitraClip therapy in daily clinical practice: initial results from the German transcatheter mitral valve interventions (TRAMI) registry. Eur J Heart Fail 2012;14:1050-5.

8 Stone GW, Lindenfeld J, Abraham WT, et al. Transcatheter mitral-valve repair in patients with heart failure. $N$ Engl $J$ Med 2018;379:2307-18.

9 Søndergaard L, Gustafsson F. The Potential Role of Transcatheter Heart Valve Interventions in Heart Failure Treatment. JACC Cardiovasc Interv 2019;12:166-8.

10 Boekstegers P, Hausleiter J, Baldus S, et al. Interventionelle Behandlung Der Mitralklappeninsuffizienz MIT dem MitraClip®Verfahren: Empfehlungen des Arbeitskreises Interventionelle Mitralklappentherapie Der Arbeitsgemeinschaft Interventionelle Kardiologie (AGIK) Der Deutschen Gesellschaft für Kardi. Kardiologe 2013;7:91-104.

11 Zoghbi WA, Enriquez-Sarano M, Foster E, et al. Recommendations for evaluation of the severity of native valvular regurgitation with twodimensional and Doppler echocardiography. J Am Soc Echocardiogr 2003:16:777-802.

12 Fukuda S, Saracino G, Matsumura Y, et al. Three-Dimensional geometry of the tricuspid annulus in healthy subjects and in patients with functional tricuspid regurgitation: a real-time, 3-dimensional echocardiographic study. Circulation 2006;114:1492-8.

13 Notomi Y. To meet the unmet needs. Eur Heart J Cardiovasc Imaging 2018;19:498-500.

14 Nath J, Foster E, Heidenreich PA. Impact of tricuspid regurgitation on long-term survival. J Am Coll Cardiol 2004;43:405-9.

15 Sadeghpour A, Hassanzadeh M, Kyavar M, et al. Impact of severe tricuspid regurgitation on long term survival. Res Cardiovasc Med 2013;2:121-6.

16 Maekawa E, Inomata T, Watanabe I, et al. Prognostic significance of right ventricular dimension on acute decompensation in chronic leftsided heart failure. Int Heart $J$ 2011;52:119-26.

17 Pavasini R, Ruggerini S, Grapsa J, et al. Role of the tricuspid regurgitation after mitraclip and transcatheter aortic valve implantation: a systematic review and meta-analysis. Eur Heart $J$ Cardiovasc Imaging 2018;19:654-9.

18 Tigges E, Blankenberg S, von Bardeleben RS, et al. Implication of pulmonary hypertension in patients undergoing MitraClip therapy: results from the German transcatheter mitral valve interventions (TRAMI) registry. Eur J Heart Fail 2018;20:585-94.

19 Di Mauro M, Bivona A, lacò AL, et al. Mitral valve surgery for functional mitral regurgitation: prognostic role of tricuspid regurgitation. Eur J Cardiothorac Surg 2009;35:635-40.

20 Godino C, Scotti A, Taramasso M, et al. Two-year cardiac mortality after MitraClip treatment of functional mitral regurgitation in ischemic and non-ischemic dilated cardiomyopathy. Int $J$ Cardiol 2018;269:33-9.

21 Besler C, Blazek S, Rommel K-P, et al. Combined Mitral and Tricuspid Versus Isolated Mitral Valve Transcatheter Edge-to-Edge Repair in Patients With Symptomatic Valve Regurgitation at High Surgical Risk. JACC Cardiovasc Interv 2018;11:1142-51. 